\title{
La corte del califa. Cuatro años en la Córdoba de los omeya
}

FICHA BIBLIOGRÁFICA

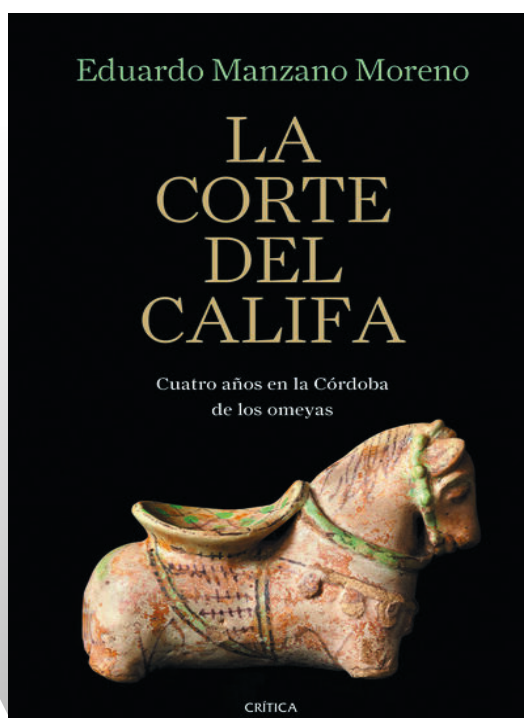

Eduardo Manzano Moreno, La corte del califa. Cuatro años en la Córdoba de los omeyas, 2019, Crítica, Serie Mayor, Barcelona, 475 págs. ISBN: 978-84-9199-028-4

Jorge Elices Ocón I Universidad Federal de Sao Paulo

LA POSIBILIDAD DE TRAZAR UNA RADIOGRAFía de las sociedades antiguas en la que se capture un momento enigmático, descubriendo lo que había antes y señalando lo que va a acontecer posteriormente, constituye un ejercicio complejo por múltiples motivos. Las fuentes disponibles no siempre contienen los elementos necesarios para reconstruir, de modo fidedigno, la sociedad particular que queremos retratar. Si, además, la radiografía se centra en el Califato de Córdoba, fundado por 'Abd al-Raḥmān III en el año 929, y en su momento de máximo apogeo político, económico y cultural, puede haber más dudas. ¿Qué fuente atesti- 
gua este instante de esplendor y, al mismo tiempo, nos permite atisbar los problemas que se avecinarán posteriormente?

La corte del califa es realmente una radiografía del Califato de Córdoba (p. 29) en un momento muy preciso, entre los años 971 y 975 , merced a una fuente muy particular, unos anales que escribió 'Īsà b. Aḥmad al-Rāzì (m. 985), recopilados y complementados por Ibn Hayyān (m. 1076) en el verano de 1009 para componer el volumen séptimo de su Muqtabis (Introd. pp. 25, 136, 386, nota 1$)^{1}$.

Este texto no está exento de problemas. En él se da cuenta de todo lo que sucede en la corte del califa al-Hakam II: nombramientos o destituciones de funcionarios, embajadas, hambrunas, desfiles, victorias, derrotas y enfermedades. Son numerosos nombres y referencias, tantas que no siempre resulta posible identificar cada uno de ellos y conseguir deducir la importancia de lo que el texto nos consigna. Sin embargo, E. Manzano nos guía perfectamente, nos traslada en el tiempo y nos muestra la radiografía de un califato fuerte y en apogeo, que acaba fracasando ${ }^{2}$. Algo sucede entre 971 y 975 que precipita el final. Un año después de concluir el texto de 'Īsà b. Aḥmad al-Rāz, en 976, muere el califa al-Hakam II. En los años posteriores, el heredero queda apartado del ejercicio del poder por Muhammad b. Abī 'Āmir (Almanzor). Tras la muerte de éste, seguida de la de su hijo y sucesor, estalla una guerra civil o fitna, que comienza en el año 1009, momento en el que escribe que Ibn Hayyān, que no puede dejar de comentar qué fue lo que se torció para que el califato fracasara y acabara por disolverse en el año 1031.

A medida que avanza el libro se vislumbran los puntos de inflexión que dieron al traste con el proyecto político de los Omeyas, descubrimos los resortes del poder y sus detentadores, la estructura administrativa, los cargos que ocupaban y las personas que se vieron arrastradas por los acontecimientos y la que los amoldaron a sus dictados.

El libro se puede dividir a mi juicio en dos partes. La primera nos presenta el estado califal como una maquinaria compleja, burocratizada, capaz de recabar y emplear recursos y riquezas ingentes, pero que al mismo tiempo sufría tensiones o contradicciones llamativas (cap. 1-4). La segunda parte está dedicada al desarrollo de los acontecimientos que tuvieron lugar entre los años 971 y 975 mostrando las consecuencias que se derivaron de ellos (cap. 5-10). En un momento concreto, el verano del año 971, tuvo lugar "un suceso que desencadenó una serie de inesperadas consecuencias" y sobre el que el texto "ofrece un relato muy detallado de estos hechos [...] lo que nos permite conocer lo ocurrido con un detalle muy poco frecuente para la época" (p. 171).

1. Ibn Hayyān, Muqtabis VII: al-Muqtabis fì ajbār balad al-Andalus, ed. 'A. R. al-Haŷŷ̀, Beirut, 1965 y trad., El califato de Córdoba en el "Muqtabis" de Ibn Hayyān. Anales palatinos del califa de Córdoba al-Hakam II, por 'Īsà b. Aḥmad al-Rāzī (360-364=971-975 J. C.), por E., García Gómez, Madrid, 1967.

2. En este sentido resulta fundamental consultar las notas al pie de la obra (pp. 347-427) donde el autor aprovecha para complementar los detalles mencionados en el texto con datos arqueológicos, referencias bibliográficas, correcciones a la traducción de E. García Gómez e identificando topónimos y personajes mencionados. Además, la obra se completa con imágenes, mapas y apéndices (pp. 337-345). 
La primera parte se centra en analizar el estado (sultān) califal. Pese a las reticencias que pueda suscitar el empleo de la palabra "estado" en fechas tan tempranas, E. Manzano sostiene, y el libro en sí es prueba de ello, que cabe hablar de estado en al-Andalus. Se trata de una aportación interesante. Desarrollando las tesis de H. Kennedy y Ch. Wickham, el autor entiende sulțān como "el poder central encarnado en el califa, pero que desborda su persona" (p. 93) o "la estructura administrativa y militar que tiene al califa como su figura visible (...) pero que cuenta también con una existencia y un funcionamiento dotados de una lógica propia” (p. 94)3.

El control que ejercía este estado califal en al-Andalus es la idea que vertebra los cuatro primeros capítulos del libro. El primero de ellos está dedicado a los ciclos físicos y humanos, marcados por el trabajo y la religión, que regulaban la vida de la población y la corte. Quizás lo más relevante sea señalar que el funcionamiento del estado estaba garantizado frente a viento y marea, pues era capaz de tener conocimiento de lo que ocurría en cada región y socorrer a los súbditos en caso de necesidad (p. 44), de estimar y evaluar el alcance de las pérdidas en las cosechas y obtener, pese a ello, el máximo rendimiento fiscal y productivo (p. 48-49).

En el segundo capítulo, E. Manzano pone de manifiesto que el estado califal era una auténtica maquinaria de captación de recursos, centralizada, con una efectividad e intensidad nunca antes vista (p. 61). En total los ingresos alcanzarían los seis millones de dinares (p. 61-63), una suma astronómica, destinada a sufragar grandes construcciones, campañas militares, el aparato burocrático-estatal y la política omeya. La munificencia del califa le permitía aglutinar en torno a su figura a las principales familias e intereses de al-Andalus, eso sí, a un coste muy elevado (p. 83). Los talleres califales produjeron en estas fechas algunos de los objetos de arte más bellos y elaborados hasta la fecha. La mayoría de ellos eran regalos que desempeñaban un papel fundamental en la política diplomática del califato con los reinos cristianos y los caudillos tribales beréberes (pp. 67-77).

El tercer capítulo está dedicado a analizar los resortes que componía el estado, es decir, quiénes ejercían los cargos de poder (pp. 97-8 y 105-111), su estructura y funcionarios principales (pp. 112-119). Existía una figura, el șāhib al-mazālim, que recogía las quejas y denuncias de la población, pero no parece que la institución fuera completamente efectiva. La corrupción restaba credibilidad al sistema. La solución pasó por incorporar a la administración a ulemas, hombres sabios distinguidos por sus conocimientos sobre religión y derecho islámico, con un gran prestigio social, como forma de ejercer un control más estrecho y legítimo (pp. 100-101).

El cuarto capítulo se centra en el ejército o ŷund. Al incrementarse la presencia del estado en todos los rincones de al-Andalus, también en la frontera, surgió la necesidad de disponer de tropas de manera constante y recurrente en diferentes frentes. El ejército tradicional, el ŷund, cada vez se mostraba más inoperante en este sentido. La defensa de la frontera quedó

3. En la página 365, notas 7 y 10 pueden verse las referencias de E. Manzano, citando una conferencia de H. Kennedy pronunciada en Princeton titulada "What does sulțān mean in 10th century?". Igualmente cita a P. Guichard, Al-Andalus frente a la conquista cristiana, 383-387, donde señala que sulțān encarna” cierta idea de estado"; así como Ch. Wicham, Una nueva historia de la Alta Edad Media, 113-115. 
poco a poco en manos de familias locales, con intereses propios (p. 134) y nuevas tropas, bereberes, fueron reclutadas (p. 137).

El estado califal era pues una estructura compleja y desarrollada, no exenta de problemas y contradicciones, por otra parte habituales en un estado fuerte y burocratizado que gestiona grandes recursos. Para mantener esta estructura era necesario una presión fiscal alta e incluso, que varios de los impuestos recaudados fuesen, en realidad, ilegales según la ley islámica. De este modo, el califa, que sustentaba su legitimidad en el respeto a la ortodoxia (y en garantizar su cumplimiento), era el primero en incumplirla. Además, no todos eran iguales ante el fisco: un caudillo bereber del Norte de África pagaba una cantidad de impuestos testimonial, ajustada a los cánones islámicos, mientras que la población andalusí debía hacer frente a pagos mucho mayores. (pp. 64-67).

A medida que aumentaba la complejidad del estado, el califa necesitaba hombres leales en los que confiar la toma de decisiones. Las grandes familias fueron relegadas y, en su lugar, ocuparon los puestos de la administración esclavos șaqāliba, eunucos, clientes (mawālì) de origen esclavo, y figuras de origen humilde, pero leales al califa (p. 105). Además, no todos se beneficiaron por igual de los recursos y bienes amasados por el estado. Las contradicciones reaparecen aquí: un pluriempleado funcionario de la frontera conseguía sumar treinta dinares de sueldo, mientras que dos destacados personajes como Ŷa 'far y Yahyà ibn al-Andalusī, recibieron una pensión de 192.000 monedas de plata al año. Estas diferencias tan señalas crearon rencillas y conflictos en el seno del califato (83-85).

En cualquier caso, estas contradicciones y problemas eran preocupantes, pero no graves. Sin embargo, en el periodo comprendido entre 971 y 975 , algunas decisiones tomadas resultaron ser fatales y ahondaron en estos problemas. El punto de inflexión se produjo en el verano del 971. Entonces, el califa fatimí, la dinastía shií y rival de los Omeyas en el Norte de África, que acababa de conquistar Egipto, decidió trasladarse al país del Nilo y dejar como lugarteniente en la región a Zīrī b. Manād. Su rival, Ŷa 'far ibn al-Andalusī, que esperaba esa designación, se vio así desplazado del poder y optó por desertar y cambiar de bando, siendo recibido en Córdoba como un aliado inesperado, pero con toda clase de beneficios, como hemos visto (pp. 171-175).

El giro en los acontecimientos suponía una oportunidad política única. El capítulo quinto está dedicado por entero a ilustrar al lector acerca de la rivalidad entre las dos dinastías, el éxito cosechado por los Fāțimíes y la amenaza que encarnaban, guiándonos hasta este preciso momento. E. Manzano sostiene que ya no se trataba solo de un enfrentamiento entre dos dinastías, sino que, en realidad, con el califato 'abbāsí en franca decadencia y desprestigio, se estaba dirimiendo el liderazgo del mundo islámico. Podemos entender así el recibimiento dado a Ŷa 'far y Yahyà ibn al-Andalusī y, como subraya el autor, "la decisión más trascendental" y "sin precedentes" que tomó al-Hakam II: ordenó enviar al ŷund al Norte de África (p. 177-178).

Los capítulos sexto y séptimo desarrollan los acontecimientos que relata el texto de 'İsà b. Aḥmad al-Rāzī. Se trataba de una apuesta arriesgada, pero la decisión refleja la política ambiciosa de un estado que deseaba consolidar su dominio en la región y doblegar a sus enemigos. Sin embargo, las tropas desplegadas, que debían someter a un rebelde de la región, Hasan ibn Qannūn, fueron derrotadas de forma estrepitosa en Diciembre de 972 (p. 180). 
Pese a ello, el califa no se retiró, sino que redobló esfuerzos y gasto militar. Las cifras del contingente movilizado y de las sumas destinadas al pago de las soldadas y a regalos que habrían de traducirse en alianzas diplomáticas evidencia la importancia que se le daba a la decisión y el momento político (pp. 183-190).

La estrategia dio resultado y el rebelde fue sometido ya en el 974. Los poetas de la corte cantaron el triunfo y auguraban nuevos éxitos (pp. 190-196), pero en realidad lo conseguido había sido muy poco y, además, los problemas, ahora en otros frentes, se multiplicaron. Por un lado, la amenaza de los vikingos (201-206), y por otro lado, los reinos cristianos (pp. 206-210). Los califas habían llevado a cabo un cambio de estrategia. Reforzaron el sistema defensivo, delegaron la defensa en las familias locales (pp. 210-216) y confiaron su estrategia a la diplomacia y los regalos de los que la crónica da buena cuenta: recepciones, delegaciones, regalos (pp. 216-224). Sin embargo, aprovechando que el ejército califal en el Norte de África y la propia debilidad del califa, que había sufrido un ictus el 30 de Noviembre del 974, los cristianos orquestaron una coalición que puso asedio a la fortaleza de Gormaz en Abril del 975 (pp. 224-226). El asedio se resolvió de forma inesperada: el ataque frontal de los cristianos fue repelido por los defensores. Sin embargo, la victoria se debió más a las propias desavenencias entre los cristianos que a la política diplomática del califa, que se había revelado como un auténtico fracaso (pp. 229-230).

En este esfuerzo bélico sostenido durante más de tres años hubo además un cambio trascendental: si hasta el año 972 el califa al-Ḥakam II se había mostrado reticente y lleno de aversión hacia los jinetes bereberes, en el trascurso de la guerra en el Norte de África, el califa cambió de opinión y se transformó en el más entusiasta defensor de su destreza (p. 137-138) y pese a su impopularidad entre la población, y aunque a veces plantearan serios quebraderos de cabeza (algunos de ellos eran jāriŷíes, opuestos a la legitimidad que encarnaba el califa), el califa comenzó a contratarlos y enrolados en el ejército. La decisión respondía a las pautas del momento, marcadas por el predominio de la caballería como arma fundamental de combate (pp. 143-149), así como a las necesidades militares crecientes, con múltiples frentes abiertos (p. 149). Sin embargo, tuvo importantes consecuencias.

Ibn Hayyān, comentando el texto de Isa en el año 1009, señala este cambio como clave para entender los problemas de su tiempo y E. Manzano recoge el testimonio del historiador y subraya su importancia para entender las consecuencias posteriores que se derivaron de este hecho (p. 141-142). Muhammad b. Abī 'Āmir (Almanzor), fue el gran beneficiado por los acontecimientos (p. 198). Era hijo de una familia árabe notable, pero de provincias, destinado a ocupar un cargo en la administración estatal. Sin embargo, tuvo suerte y perspicacia para ganarse el apoyo de las grandes familias, desplazadas de la administración por el califa (p. 122-123) y para aunar sus propias redes clientelares y relaciones políticas en el Norte de África, donde desempeñó el cargo de cadí en el trascurso de la guerra africana (p. 198). Una vez aupado al poder, Muḥammad b. Abī 'Āmir se deshizo de sus rivales y disolvió el ŷund. En su lugar confió las campañas militares a estos jinetes bereberes que compusieron la columna vertebral de su ejército. Emprendió entonces una serie de campañas militares contra los reinos cristianos, cambiando de nuevo la estrategia, atacando enclaves con los que hasta entonces había predominado un entendimiento, como el caso del Condado de Barcelona. Tras su muerte, y la de su hijo y sucesor, el sistema se desmorona. El ejército bereber, considerado 
la solución al problema, fue una fuerza militar que desempeñó un papel trascendental en la fitna y que incluso acabó saqueando Córdoba en el año 1013. Los cristianos fueron contratados como mercenarios para aupar a distintos califas. Uno de ellos, el conde Sacho García de Castilla recibió en pago el castillo de Gormaz. Con ello la quiebra del sistema defensivo fue solo cuestión de tiempo y en el año 1085 los cristianos conquistaban Toledo (pp. 232-234) ${ }^{4}$.

Los últimos capítulos del libro (cap. 8-10) son una especie de epílogo en el que se nos muestra la concepción del poder por parte de los Omeyas, su representación y topografía sobre el paisaje y la ciudad, para luego ofrecernos una imagen muy distinta: su abrupto final. Estos capítulos narran también los últimos acontecimientos del año 975, y señalan el desenlace final de al-Hakam II y del estado califal. El ictus que sufrió el califa en Noviembre del 974 supuso un punto de inflexión en este sentido. Al-Hakam II quedó recluido en sus habitaciones privadas y solo recuperó su actividad pública a comienzos del año 975. E. Manzano señala que, a partir de entonces, la necesidad de determinar su sucesión fue una prioridad para el califa (p. 259 y 265). El problema era que su hijo Hišām era menor de edad, lo que impedía que pudiera desempeñar el cargo o incluso que fuera designado heredero. Para ver su voluntad cumplida hubo de quebrar algunos de los presupuestos imperantes hasta entonces en el ejercicio del poder.

La ideología de los omeyas era "pragmática" (p. 236). El califa se presentaba ante la comunidad o umma como buenos gobernantes, garantes de los principios del Islam y la tradición del profeta, como Comendador de los Creyentes (pp. 249-252), pero también, y esto es interesante, tal y como subraya E. Manzano, asegurando la prosperidad y el bien común o interés general (mașlaha) de sus súbditos (p. 239).

Esta ideología quedaba plasmada en una topografía del poder acorde a sus necesidades. La ciudad palatina de Madinat al-Zahrā' fue el escenario donde se representaba el poder del califa (pp. 321-329). La decoración vegetal del Salón Rico de Madinnat al-Zahrä’ (pp. 242-248) celebraba la prosperidad que emanaba del Califa (p. 246). Las ceremonias y triunfos llevados a cabo en la ciudad palatina ensalzaban a la dinastía y al califa y ratificaban la ideología política y religiosa en una gran escenografía del poder (pp. 276-292). El esfuerzo de reconstrucción llevado a cabo aquí por E. Manzano y aporta una notable revisión con respecto a los trabajos de M. Acién Almansa, M. Barceló o M. Fierro5. Especialmente interesante es el apartado dedicado a los símbolos de poder y las banderas (pp. 295) que suponen un punto de partida para diversos estudios.

4. Las refrencias sobre Muhammad b. Abī 'Āmir a las que hace E. Manzano proceden de la obra de X. Ballestín Navarro: Al-Mansūr y la dawla 'amiriya. Una dinámica de poder y legitimidad en el Occidente musulmán medieval, Barcelona, 2004.

5. E. Manzano cita (p. 402, nota 35, p. 408, nota 16 y 426, nota 98) los trabajos de M. Acién, "Materiales e hipótesis para una interpretación del Salón de Abd al- Rahman al-Nasir”, en Vallejo, A. (coord.), Madinat al-Zahara: El Salón de Abd al-Rahman III, Córdoba, 1995, 177-195; M. Barceló, "El califa patente. El ceremonial omeya de Córdoba o la escenificación del poder" en Vallejo, A. Madīnat al-Zahrā. El Salón de 'Abd al-Raḥmān III, Córdoba, 1995, 153-175; M. Fierro, "Madinat al-Zahara', el paraíso y los fatimíes", AlQantara, 25, 2, 2004, 299-328. 
Junto con Madinat al-Zahrā', Córdoba era el otro centro de poder de los Omeyas. E. Manzano ofrece un panorama de la ciudad durante estos años trascendentales del califato (pp. 301-321) en base a las excavaciones arqueológicas llevadas a cabo en los últimos años (mapas en p. 299 y 303) ${ }^{6}$. Tienen especial interés las páginas dedicadas al zoco cordobés (p. 309-312), poco estudiado hasta ahora, así como las almunias y el entorno suburbano (pp. 312-321), sobre el que cada vez tenemos más información. Si hay un rasgo a destacar es la intervención de los califas en organizar el espacio urbano (pp. 309, 316, 318, 320, 331), una idea que ya habían señalado M. Acién y A. Vallejo ${ }^{7}$, pero que el autor desarrolla, en conexión con la preocupación de los califas por el interés común y el control del estado en todos los resortes de la vida en al-Andalus.

En este marco, el problema de la sucesión de Hišām se revela como una situación que habría de poner a prueba los resortes del poder. Algunos de los presupuestos de la ideología omeya hubieron de quebrarse necesariamente para conseguir que su designación como heredero pudiera llevarse a cabo. Para ello se recurrió a toda una serie de tretas y actos. Por un lado, la reducción en un sexto del impuesto por la exención del servicio militar (pp. 50 y 262) o el reparto de dinero a la multitud por parte de padre e hijo desde la azotea de la puerta de la Azuda del Alcázar (p. 264), buscaban la aquiescencia de la umma, tan necesaria como como su sumisión (p. 240-241). Un sutil golpe jurídico sirvió también para allanar el camino a la sucesión, ya estudiado por A. García Sanjuán ${ }^{8}$ : la firma de un acta de manumisión de varios esclavos en la que aparecía la firma de Hišām como testigo (pese a no ser adulto) y "candidato a heredero", junto con la firma estampada por otros testigos ilustres, los hermanos del califa y varios altos cargos, que de esta forma reconocían el acto (pp. 256-265).

La voluntad del califa se cumplió, pero solo a medias. Su hijo legó a ser califa con el nombre de Hišām II. Sin embargo, "a pesar de la enorme contundencia con la que llegó a expresarse, el proyecto de 'Abd al-Raḥmān III y al-Ḥakam II no llegó a obtener un respaldo unánime. La contestación interna frente a decisiones y políticas de ambos califas acabó fraguando en una facción política muy amplia e influyente que concibió el proyecto de impedir que todo el aparato del estado dependiera del califa y de una camarilla de servidores esclavos ligados a su persona" (p. 329). Muḥammad b. Abī "Āmir (Almanzor) acabó detentando el poder, gracias al apoyo inicial de este grupo de familias que habían monopolizado la administración tradicionalmente y ahora se veían excluidas y desplazadas. Madinat al-Zahrä, la

6. E. Manzano cita los trabajos de A. León y F. J. Murillo, especialmente los contenidos en: Vaquerizo, D. y Murillo, J. F. (eds.), El anfiteatro romano de Córdoba y su entorno urbano. Análisis arqueológico (ss. I-XIII d.C.), Córdoba, 2010.

7. Acién Almansa, M. y Vallejo Triano, A. “Urbanismo y Estado islámico. De Córdoba a Qurțba-Madinat al-Zahrā”, en Cressier, P. García-Arenal, M. y Méouak, M. Genèse de la ville islamique en al-Andalus et au Maghreb occidental, Madrid, 1998, 107-136.

8. A. García Sanuán, "Legalidad islámica y legitimidad política en el califato de Córdoba: la proclamación de Hišām II (360-366/971-976)”, Al-Qantara, 29, 1, 2008, 45-77.

Revista de historiografía 33, 2020, pp. 261-269 
ciudad que escenificaba el poder del Califa y su legado, se convirtió en la jaula dorada de Hišām (p. 329). Almanzor decidió construirse su propia capital: Madīnat al-Zāhira.

El sistema impuesto supuso una drástica revisión de la política llevada a cabo por los Omeyas hasta ese momento. Los triunfos militares parecían ratificar lo acertado de sustituir el ejército tradicional por contingentes bereberes, sin embargo, tras la muerte de Almanzor y de su hijo, estalló el conflicto. En 1009, los planes para conferir la dignidad califa a un hijo de Almanzor dieron pié a una conjura liderada por un descendiente de 'Abd al-Raḥmān III. La plebe ('āmma) asaltó el Alcázar de los Omeyas, saqueó el Madinat al-Zähira y posteriormente Madinat al-Zahrä'. Luego le llegaría el turno a los bereberes. El proyecto de los Omeyas, plasmado en el estado califal, quedó disuelto y en ruinas (p. 334).

El libro concluye aquí y al lector quizás le sepa a poco. Las preguntas que sugiere la lectura son varias y animarán, a buen seguro, el debate académico. ¿De qué manera se produjo este final y quiénes fueron sus protagonistas? ¿ Oculta 'Īsà b. Aḥmad al-Rāzī informaciones o detalles contrarias a los Omeyas, que ahondaran en el malestar o el hartazgo de la élite (jāsșa) o la plebe ( 'àmma) y que explicarían el violento final del califato? ¿Por qué, pese a que podemos encontrar problemas similares en el califato 'abbāsí o fātịimí, el califato de los omeyas acabó sucumbiendo? ¿Qué legado quedó del proyecto omeya y de qué manera fue un recurso político, no solo para los musulmanes, sino también para los cristianos, que habían acudido a Madinat al-Zahrä' y habían recibido los fabulosos regalos del califa?

Algunas de estas preguntas sobrevuelan la obra de E. Manzano, quien dedica un pequeño pero interesante apartado a las difamaciones y maledicencias lanzadas contra el califa (pp. 252-256), señalando incluso que un cronista de la corte como 'Īsà b. Aḥmad al-Rāzī no pudo omitir la cuestión y dejó constancia de que existían ciertas "historias (ajbār) que circulaban" (p. 253), relacionadas con su vida privada (en relación a la madre del heredero, Șubh), pero también contra su política, revelando la existencia de una oposición (p. 256). Sabemos además que el califato tenía un grave problema de credibilidad frente a sus súbditos y que, pese a velar por el bien común o interés general (mașlaha) de sus súbditos, existía un rechazo a la presión fiscal, a los desmanes de la corte y a las tropas bereberes. Esto quizás marca una diferencia importante con respecto al califato 'abbāsí, donde pese a que el califa quedó también relegado a las sombras y el poder fue ejercido por distintos jefes militares, también impopulares, el estado califal perduró hasta $1255^{9}$. En el caso de Córdoba me resulta especialmente interesante la participación de la plebe ('āmma) en las revueltas y motines del año 1009 y que quizás deben ponerse en relación con el peso político que tenía la umma dentro de la concepción política del poder por los omeyas, según señala E. Manzano (p. 241) ${ }^{10}$.

9. H. Kennedy escribió hace unos años un libro centrado en el califato 'abbāsí durante los siglos VIII y IX al que tituló también La Corte de los Califas, 2008, Barcelona.

10. En este sentido, resulta interesante el estudio de F. Amabe, Urban Autonomy in Medieval Islam. Damascus, Aleppo, Córdoba, Toledo, Valencia and Tunis, 2016, Leiden, analizando el caso cordobés (pp. 85117) en el que se resalta justamente esta peso político de la umma. 
En definitiva, La Corte del Califa contiene una revisión importante acerca del califato omeya, la figura de al-Ḥakam II y la obra de 'Īsà b. Aḥmad al-Rāzī. Se trata de un trabajo notable, exhaustivo en lo referente a la identificación de nombres, topónimos y conceptos, que contempla nuevas hipótesis y perspectivas de estudio, lo que hace de esta obra, una referencia tanto para el público no especializado, como para los investigadores de distintos ámbitos de estudio. 